\section{Securing Clean, Domestic, Affordable Energy with Wind}

The U.S. Department of Energy Wind Program is committed to developing and deploying a portfolio of innovative technologies for clean, domestic power generation to support an ever-growing industry, targeted at producing $20 \%$ of our nation's electricity by 2030 .

\section{A Growing Market}

Wind energy is one of the fastest growing energy markets in the nation, contributing $6,800 \mathrm{MW}$ of new generating capacity in 2011, which comprised $32 \%$ of all new U.S. electric capacity for the year. In 2012, the total U.S. installed wind capacity reached 50,000 MW - enough to power more than 12 million homes annually or as many homes as in the entire state of California-with another 10,000 MW of additional wind farms under construction.

According to the U.S. Department of Energy's (DOE's) 2011 Wind Technologies Market Report, 38 states now have utility-scale wind projects, 14 states have installed more than $1,000 \mathrm{MW}$ of wind power, and six states now meet more than $10 \%$ of their total electricity needs with wind power. Wind energy currently represents about $3 \%$ of the nation's energy portfolio, but according to a 2008 DOE report, wind energy could contribute as much as $20 \%$ of the nation's electricity by 2030 .

\section{What We Do}

DOE Wind Program activities are leading the nation's efforts to accelerate the deployment of wind power technologies by improving performance, driving down costs, and reducing market barriers. We work with national laboratories, industry, universities, and other federal agencies to conduct research and development (R\&D) activities, providing technical and financial support through competitive selections, direct funding, and cost-sharing agreements. Our efforts target both land-based and offshore wind power to fully support the clean energy economy.

Technical innovation, which allows for larger wind turbines with longer, lighter blades, has steadily improved wind turbine performance and increased the efficiency of power generation from wind energy. At the same time, wind project capital and maintenance costs continue to decline, driving U.S. manufacturing competitiveness on the global market. The price of wind under long-term contracts signed with utilities in 2011 averaged 40\% lower than in 2010 and 50\%

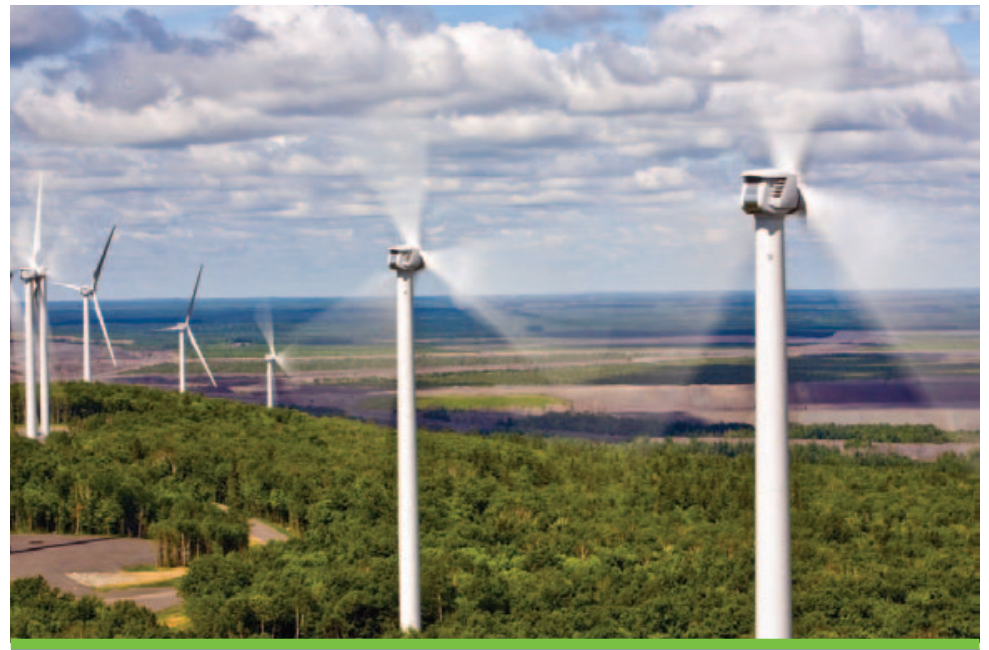

A modern wind turbine has more than 8,000 component parts. In 2011 , nearly $70 \%$ of the equipment installed at U.S. wind farms was provided by domestic manufacturers, doubling from 35\% in 2005. NREL/PIX 16051

lower than in 2009 , making wind competitive with a range of wholesale power prices seen in 2011.

By investing in improvements to wind plant design, technology advancement, and operations, as well as developing tools to identify the highest quality wind resources, the Wind Program serves as a leader in making wind energy technologies more competitive with traditional sources of energy and a larger part of our nation's renewable energy portfolio.

\section{Why It Matters}

The U.S. land-based wind resource is about 11 million megawatts (MW), and the steady winds just off America's coasts only increase that massive resource. Greater use of the nation's abundant wind resources for electric power generation will help reduce emissions of greenhouse gases and other air pollutants, diversify the country's energy supply, provide cost-competitive electricity to key regions across the country, and reduce water usage for power generation. Current wind power installations in the United States provide enough electricity to avert nearly 79 million tons of carbon dioxide emissions, which is equivalent to taking 14 million cars off the road.

In addition, wind energy deployment will help stimulate the revitalization of key sectors of the economy by investing in infrastructure and creating long-term, skilled jobs.

According to industry estimates, by the end of 2011, the wind sector employed 75,000 American workers in wind turbine 


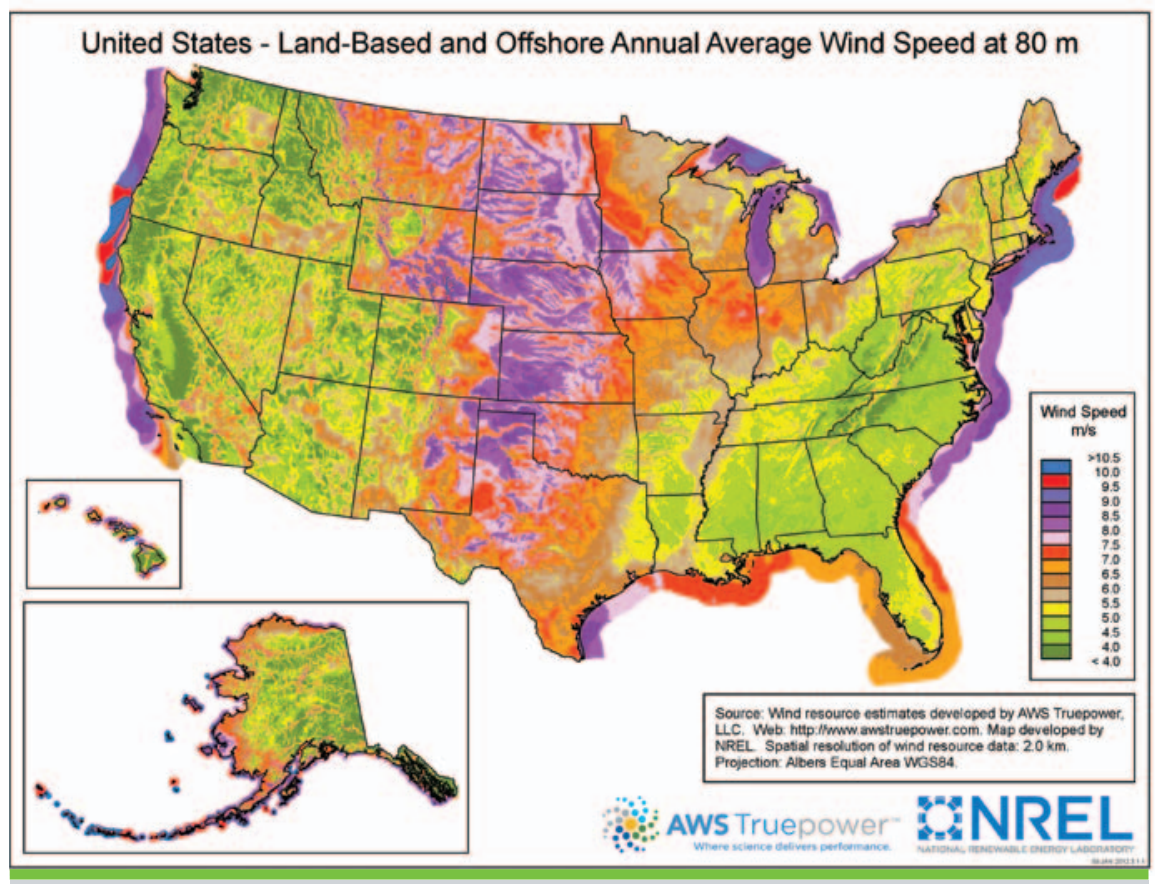

This wind resource map (available on wind.energy.gov/resource_assessment_ characterization.html) shows that most of the U.S. offshore wind resource is comparable to that found in the very windy central plains. to develop aerodynamic, structural, and electrical test centers for wind farms, wind turbines, rotor blades, and drivetrains

- Enable industry to improve performance and safety by establishing standards for small wind turbine certification

- Participate in the development of national and international wind energy standards

- Market Acceleration and Deployment

- Partner with environmental groups and agencies to understand the impacts of wind energy on bird, bat, and insect species and their habitats and with these results, take any appropriate mitigation actions

- Assist in the development of guidelines for proper wind plant siting and permitting

- Investigate and mitigate potential impacts of wind energy on society, including auditory, visual, radar, and competitive-use impacts

- Provide independent cost of energy analyses, economic assessments, and market information publications

component manufacturing, construction and installation, maintenance and operations, legal and marketing services, transportation and logistical services, and more.

To accelerate the deployment of wind power, Wind Program researchers conduct the following key activities:

- Research and Development

- Lower the cost of wind energy through R\&D activities focused on innovative wind turbine components, systems, materials, and manufacturing

- Partner with the academic community, research institutions, and industry to improve wind turbine and wind plant designs, operation, and reliability

- Facilitate the development of wind turbine systems in both land-based and offshore environments

- Explore cost reduction opportunities across all types of wind power systems

- Develop and validate open-source design tools for evaluating new concepts and educating the next generation of wind turbine designers

- Wind Turbine Testing and Certification

- Partner with industry, universities, and national laboratories
- Wind Resource Assessment and Grid Integration

- Assess domestic wind energy resources for both land-based and offshore wind energy systems

- Improve the global understanding of wind farm design conditions and complex aerodynamics

- Understand critical wind integration challenges related to electricity supply and demand, wind forecasting, and wind speed variability

- Develop solutions and best practices for wind energy grid integration

The Wind Program's investments in research, testing, market acceleration, and resource assessment efforts are helping to provide clean energy to American consumers and supporting further development of the nation's wind industry.

\section{Learn More \\ wind.energy.gov}

For more information, visit: eere.energy.gov wind.energy.gov

DOE/GO-102012-3729 • October 2012

Printed with a renewable-source ink on paper containing at least $50 \%$ wastepaper, including $10 \%$ post consumer waste.
Energy Efficiency \& Renewable Energy

\begin{abstract}
Renewable Energy
\end{abstract}

